\title{
STRAIGHT BACK SYNDROME
}

\author{
BY \\ K. K. DATEY, M. M. DESHMUKH, S. D. ENGINEER, AND C. P. DALVI \\ From the Departments of Cardiology, Medicine, and Surgery, K.E.M. Hospital, and G.S. Medical College, \\ Bombay 12, India \\ Received July 15,1963
}

Skeletal deformities of the thorax are known to produce functional disturbances of the cardiovascular system. Most of these deformities are usually benign, the only manifestation being a functional præcordial murmur. As many of these murmurs are loud, they are often detected during a routine clinical examination for symptoms not of cardiac origin, and an erroneous diagnosis of heart disease may be made. One of these skeletal deformities, the straight back syndrome, may also masquerade as heart disease. The incidence of this deformity in the general population is not known. However, it is not a rare condition, as within a period of nine months we have seen 6 patients with this condition at the K.E.M. Hospital, Bombay.

In the straight back syndrome, the anterior concavity of the vertebral column in the upper dorsal region is absent. This reduces the antero-posterior diameter of the thorax and thereby the heart and great vessels are compressed between the spine posteriorly and the sternum anteriorly (Rawlings, 1960).

\section{CASE REPORTS}

Case 1. A 40-year-old man, who was asymptomatic, was referred for a thrill and a murmur in the pulmonary area. However, there was a history of pulmonary tuberculosis about 10 years previously for which he had been adequately treated.

Physical examination revealed an asthenic man. There was a systolic thrill and a harsh grade IV* ejection systolic murmur in the pulmonary area. The pulmonary second sound was closely split and widened on inspiration. The electrocardiogram was within normal limits. The postero-anterior chest radiograph showed healed bilateral apical tuberculosis and a prominent pulmonary artery (Fig. 1A). The cardiothoracic ratio was within normal limits. The dorsal spine was straight in the lateral view and the anteroposterior diameter of the chest was reduced (Fig. 1B). Cardiac cathetrization showed normal cardiovascular hæmodynamics. The pulmonary arterial pressure was $25 / 10 \mathrm{~mm}$. $\mathrm{Hg}$; there was no evidence of a shunt, nor of a gradient across the pulmonary valve.

Case 2. A 19-year-old man was referred for palpitation and chest pain of five months' duration. A chest radiograph, taken five months previously for pain in the back, had shown a rounded opacity in the right upper zone. Physical examination showed a well-built, well-developed adult man. Abnormalities on physical examination were limited to the cardiovascular system. A prominent right ventricular impulse was palpable in the parasternal region. A grade III ejection systolic murmur was heard in the pulmonary area, which diminished in intensity on deep inspiration and in the sitting position. The second sound in the pulmonary area was loud, normally split, with normal respiratory variations. The electrocardiogram was within normal limits. The chest radiograph showed a rounded opacity in the right upper zone, a straight dorsal spine, and narrow antero-posterior diameter of the chest with impingement of the cardiac shadow

* Murmurs have been graded according to the classification of Levine and Harvey (1959). 
against the sternum. Cardiac catheterization showed normal cardiac hæmodynamics; the pulmonary artery pressure was $20 / 9 \mathrm{~mm}$. $\mathrm{Hg}$, and there was no evidence of shunt or of stenosis.

Case 3. A 25-year-old man was referred because of a cardiac murmur which was detected during routine examination for a common cold. He was a thin man with a narrow chest. A grade I systolic murmur was audible in the pulmonary area. The heart sounds were normal in intensity, and the second sound showed normal splitting. The murmur disappeared completely in the sitting position and on deep inspiration. The dorsal spine was straight. The electrocardiogram was within normal limits. The chest radiograph (Fig. 2A and $B$ ) showed a narrow antero-posterior diameter of the thorax with straight upper dorsal spine.

Case 4. An 11-year-old girl was admitted to the K.E.M. Hospital with a history of cough with expectoration. Physical examination showed a straight upper dorsal spine with narrow antero-posterior diameter of the chest. There were râles at the right base, suggesting bronchiectasis. A grade II systolic murmur was heard in the pulmonary area with a normally split second sound. The murmur disappeared completely on inspiration and in the sitting position. The electrocardiogram was within normal limits. The chest radiograph confirmed the clinical findings, showing a straight dorsal spine with narrowed A-P diameter. At the right base there were changes suggestive of bronchiectasis, which was confirmed by a bronchogram.

Case 5. A 42-year-old woman complained of pain in the chest of 4 months' duration. This pain bore no relation to exertion or change of posture.

Physical examination showed a well-built woman. A grade II ejection systolic murmur was present in the pulmonary area: this diminished in intensity in the sitting position and disappeared completely on inspiration. Her dorsal spine was straight. The electrocardiogram was within normal limits. The chest radiograph showed a straight dorsal spine in the lateral view.

Case 6. A 25-year-old man was referred to us as a case of mitral valve disease. There was a history of intermittent chest pain in the sternal area, but it had no relation to exertion. Dyspnœa on moderate exertion was present. The patient was thin, with a narrow chest. The apex beat was $1 \mathrm{~cm}$. outside the left mid-clavicular line. There was a grade II ejection systolic murmur best heard in the fourth intercostal space at the left parasternal edge. The murmur disappeared completely in the sitting position and on deep inspiration. The spine showed scoliosis. The electrocardiogram was within normal limits. A posteroanterior chest radiograph showed scoliosis, and the lateral view showed straightening of the spine, diminished anteroposterior diameter, and a reduction in the retro-cardiac space (Fig. 3A and B).

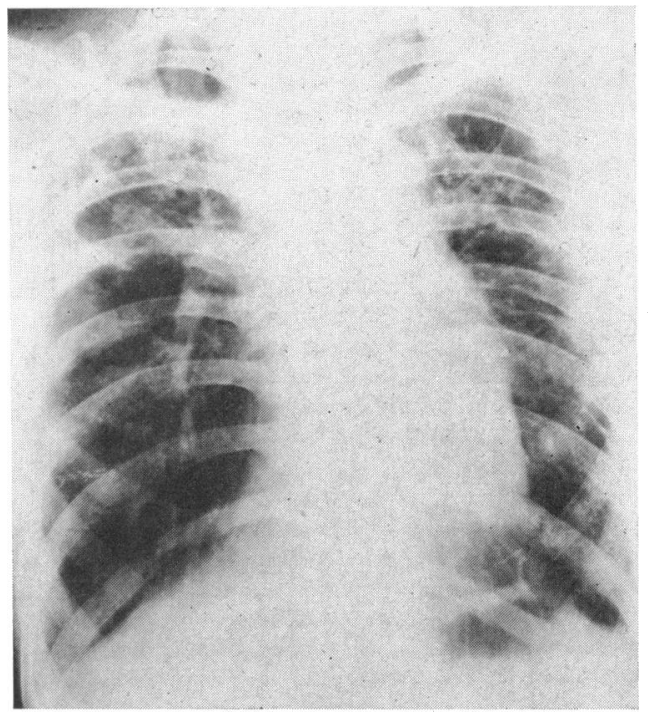

FIG. 1.-(A) Case 1. Postero-anterior view showing bilateral pulmonary tuberculosis (healed), emphysema, and normal heart size.

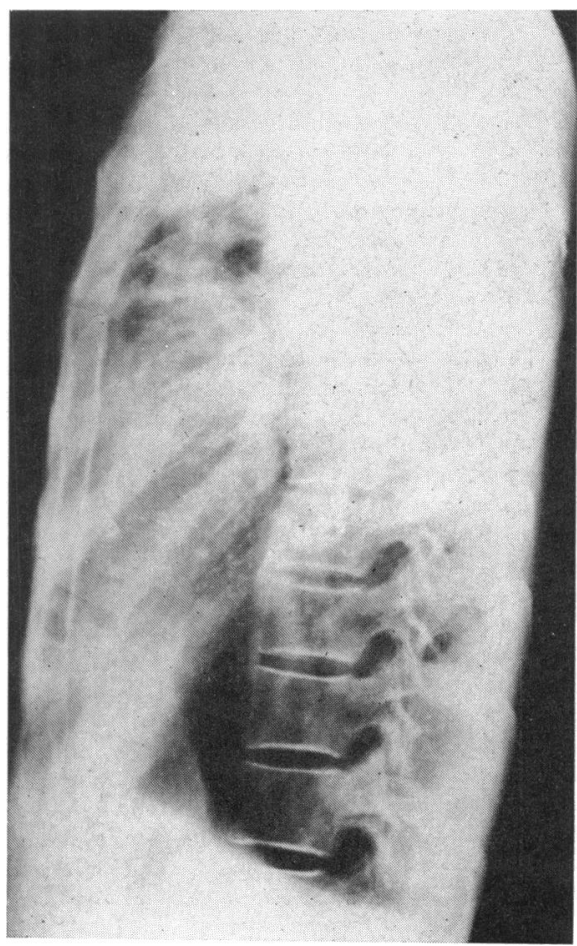

FIG. 1.-(B) Case 1. Lateral view shows a straight dorsal spine, and narrow anteroposterior diameter with diminished retrocardiac space. 


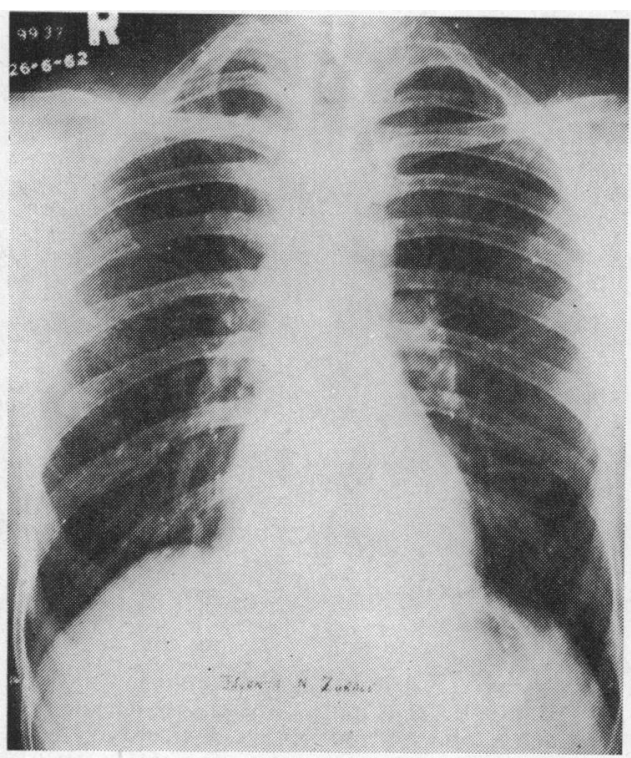

FIG. 2.-(A) Case 3. Postero-anterior view shows normal heart size and normal lung fields.

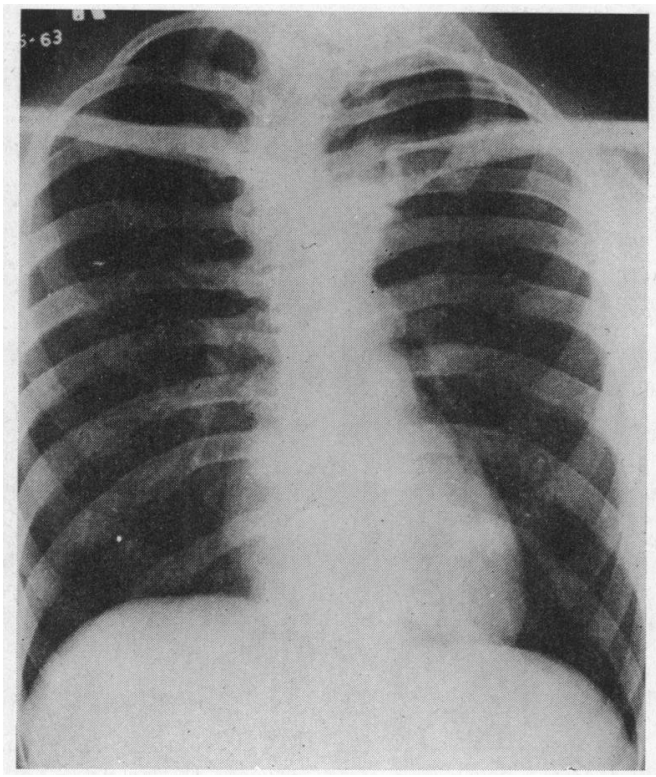

FIG. 3.-(A) Case 6. Postero-anterior view showing scoliosis of the spine and normal-sized cardiac shadow.

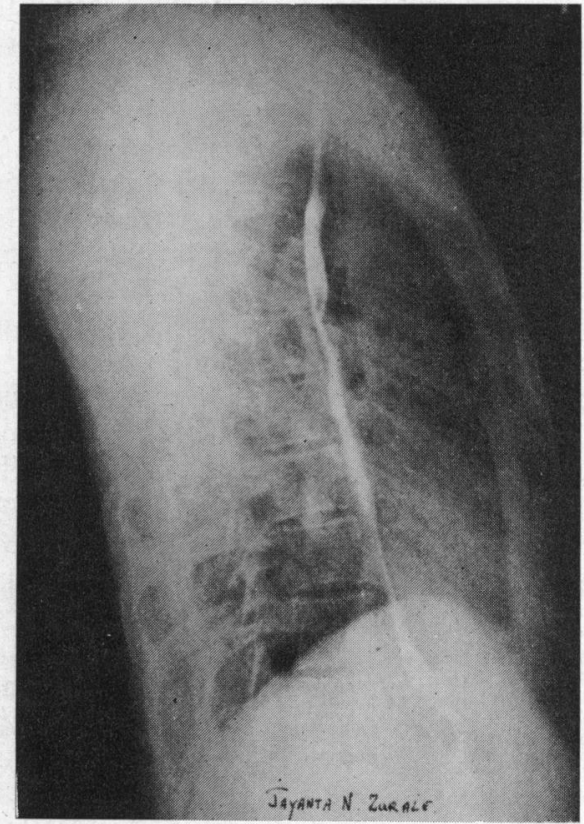

FIG. 2.-(B) Case 3. Lateral view shows straight upper dorsal spine with consequent reduction in the antero-posterior diameter of the chest.

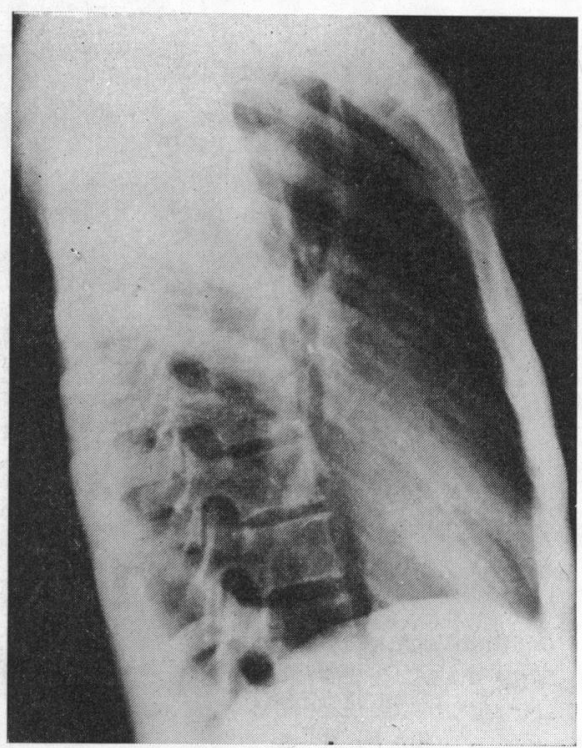

FIG. 3.-(B) Case 6. Lateral view showing straight dorsal spine and diminished antero-posterior diameter. 


\section{Discussion}

Functional disturbances of circulation caused by skeletal deformities are not uncommon, and in this communication we report six cases of a relatively new clinical entity called the "straight back syndrome" (Rawlings, 1960, 1961).

In this condition the upper dorsal spine is straight and there is a loss of the normal kyphotic curve. Due to the absence of this normal kyphosis, the distance between the sternum and the vertebral column is reduced, resulting in compression of the heart and kinking of the great vessels. This distortion seems to be maximal in the region of the waist of the heart, as in this region the great vessels that are not fixed join the relatively fixed outflow tracts of the ventricles. The right ventricular outflow tract is probably more affected because of its anterior position and its proximity to the sternum. Distortion of the outflow tract and kinking of the great vessels lead, during cardiac systole, to eddies which convert a laminar blood flow into a turbulent one and produce murmurs that are usually located in the pulmonary area. Compression of the heart between the sternum and the vertebral column gives the impression of an increase in the transverse diameter of the heart in some of the patients.

Skeletal deformities like pectus excavatum reduce the antero-posterior diameter of the thorax and also produce a similar rœntgenological appearance of enlargement of the heart in the posteroanterior view. Severe chest deformities like kyphoscoliosis may produce gross disturbances of cardiac function (Wachtel, Ravitch, and Grishman, 1956; Hanley et al., 1958), but in cases of straight back syndrome these have not been encountered by us nor have they been reported.

Persons suffering from this type of skeletal deformity are usually referred to a cardiologist for a murmur detected during routine examination for a non-cardiac condition or during a routine checkup for insurance. One of our patients was referred for palpitation, but on careful questioning it was found that the symptoms started after the patient was told by his family doctor that he had heart disease.

Physical examination usually reveals a systolic murmur often localized at the base of the heart, particularly in the pulmonary area. This murmur is of an ejection type, or it may be late in systole. The intensity varies from grade IV to grade I, usually depending on the degree of deformity. The second sound in the pulmonary area is well heard and is normally split. The murmur usually diminishes in intensity on sitting up and diminishes further on inspiration. The most significant and diagnostic finding is the straightening of the dorsal spine which is visible on inspection and can be confirmed by palpation and by a lateral radiogram of the spine.

The electrocardiogram is normal in this condition. If it is abnormal, the diagnosis of straight back syndrome should be accepted with reserve, and the possibility of an additional organic lesion should be seriously considered.

Chest radiography is diagnostic in this condition: the lateral view shows the characteristic loss of the normal curve of the dorsal spine which appears straight; the postero-anterior view shows fullness of the cardiac waist and enlargement of the heart shadow, and if a lateral view is not taken it may mislead an unwary physician into an erroneous diagnosis of heart disease. Although apparently the heart size may appear to be increased in most instances, the cardiothoracic ratio is within normal limits if the widest thoracic diameter is considered.

Case 6 had scoliosis in addition to the straight back syndrome: this appears to be a very rare combination.

Straightening of the spine causes reduction in the antero-posterior diameter of the thorax, and this is quite apparent on chest radiography in the lateral position. The widest antero-posterior distance between the spine posteriorly and the sternum anteriorly was measured in lateral teleroentgenograms in all these patients as well as the widest transverse diameter in the postero-anterior view. The ratio of transverse diameter to antero-posterior diameter was compared with that of 25 normal adults of comparable age without any skeletal deformity of the thorax. The widest transverse diameter was measured just above the right dome of the diaphragm in the posteroanterior view of the teleroentgenogram and the widest antero-posterior distance was measured in a 
TABLE

Mean Measurements of Thoracic Diameter in 25 Normal Subjects and in 6 Patients with Straight Back SYNDROME

\begin{tabular}{|c|c|c|c|c|c|c|}
\hline & & & & $\begin{array}{l}\text { Antero-posterior } \\
\text { diameter }(\mathrm{cm} .)\end{array}$ & $\begin{array}{c}\text { Transverse diameter } \\
\text { (cm.) }\end{array}$ & Ratio \\
\hline $\begin{array}{l}\text { Normal average } \\
\text { Straight back syndrome }\end{array}$ & $\begin{array}{l}\cdots \\
\cdots\end{array}$ & $\begin{array}{l}\cdots \\
\cdots\end{array}$ & $\begin{array}{l}\cdots \\
\cdots\end{array}$ & $\begin{array}{c}9 \cdot 7 \\
(7 \cdot 8 \text { to } 12 \cdot 1) \\
7 \cdot 05 \\
(5 \cdot 7 \text { to } 9 \cdot 1)\end{array}$ & $\begin{array}{c}23 \cdot 2 \\
(16 \text { to } 25 \cdot 6) \\
22 \cdot 8 \\
(20 \cdot 2 \text { to } 24 \cdot 4)\end{array}$ & $\begin{array}{c}2 \cdot 17 \\
(1 \cdot 8 \text { to } 2 \cdot 75) \\
3 \cdot 8 \\
(2 \cdot 5 \text { to } 4 \cdot 2)\end{array}$ \\
\hline
\end{tabular}

Figures in parenthesis present the range of variation.

plane parallel to that of the intervertebral space. The mean figures for these dimensions for normal subjects and for patients with the straight back syndrome are shown in the Table. The mean anteroposterior diameter was significantly smaller, while the ratio of transverse to antero-posterior diameter was significantly higher in those with the straight back syndrome than in normal subjects. A ratio of 3 or more is almost diagnostic in the absence of other thoracic deformities.

The size of the heart as seen in a teleradiogram may simulate other conditions, such as sternal depression (pectus excavatum), This deformity also reduces the distance between the spine and the sternum, and although the transverse diameter of the chest is not affected, the ratio of the transverse to the antero-posterior diameter is increased. This condition, should, therefore be considered in the differential diagnosis. However, physical examination and chest radiography both in posteroanterior and lateral positions are quite characteristic of the condition, and there is no difficulty in arriving at a diagnosis (Evans, 1946).

The presence of a murmur may suggest a ventricular septal defect, an atrial septal defect, pulmonary stenosis, or aortic stenosis. In two of our patients with the straight back syndrome, where the murmur was very loud, cardiac catheterization was performed in order to rule out the possibility of associated pulmonary stenosis or ventricular septal defect. A mild degree of pulmonary stenosis or a septal defect cannot be ruled out with certainty on clinical grounds alone, in spite of the appearance of a straight back, and further hæmodynamic data with cardiac catheterization and other diagnostic studies are sometimes needed to exclude these lesions.

Not much light has been thrown on the pathogenesis of the straight back syndrome. It appears to be congenital in origin: there is failure of development of normal adult kyphotic curve, resulting in a straight spine in the infant (Rawlings, 1960, 1961). It has also been suggested that the deformity occurs in intrauterine life during the eighth week, before ossification of the bodies of the vertebræ occur.

Probably it is a benign condition. One patient had pulmonary tuberculosis and another bronchiectasis in addition. It is difficult to speculate on the relation between the straight back syndrome and the presence of pulmonary disease, as the latter is so common in the Indian population. Since this is a relatively new clinical entity and as these patients have been followed only for a short time, we reserve our comments regarding the prognosis.

\section{SUMMARY}

Six patients with straight back syndrome are presented in this communication, and theirclinical, electrocardiographic, radiological, and cardiac catheterization findings are described.

As a result of the straightening of the upper dorsal spine, the antero-posterior diameter of the thorax is reduced resulting in compression of the heart and great vessels. These patients usually present with a systolic murmur and have no symptoms referable to the cardiovascular system. Straightening of the spine may be appreciated by palpation. The electrocardiogram and cardiac hæmodynamics are within normal limits. X-ray examination of the chest in the postero-anterior view shows widening of the waist of the heart and apparent cardiac enlargement. The lateral view is diagnostic and shows a straight dorsal spine lacking the normal slight kyphosis. The retrosternal 
space is usually obliterated and the retrocardiac space is diminished. Our data suggest that the ratio of transverse diameter of chest to antero-posterior diameter in the teleradiogram in this condition is significantly greater than that in normal subjects.

\section{REFERENCES}

Evans, W. (1946). The heart in sternal depression. Brit. Heart J., 8, 162.

Hanley, T., Platts, M. M., Clifton, M., and Morris, T. L. (1958). Heart failure of the hunchback. Quart.J. Med., $27,155$.

Levine, S. A., and Harvey, W. P. (1959). Clinical Auscultation of the Heart, 2nd ed. Saunders, Philadelphia and London.

Rawlings, M. S. (1960). The "straight back" syndrome. A new cause of pseudoheart disease. Amer. J. Cardiol., 5,333 .

- (1961). Straight back syndrome. A new heart disease. Dis. Chest, 39, 435.

Wachtel, F. W., Ravitch, M. M., and Grishman, A. (1956). The relation of pectus excavatum to heart disease. Amer. Heart J., 52, 121. 